\title{
Predictors of Gestational Weight Gain in Mexican American Women in Los Angeles
}

\author{
Ruth Mielke and Nicholas Gorman \\ California State University, Fullerton School of Nursing
}

\begin{abstract}
Background and Significance: Extremes of gestational weight gain (GWG) are associated with newborn and pregnancy complications, postpartum obesity and chronic illnesses. In the United States, Mexican American women are the largest subgroup of Hispanics but have been studied least often. The purpose of the study was to determine the prevalence, characteristics, and predictors of GWG in Mexican American women. Methods: A retrospective, correlational design used data from charts $(n=684)$ in a federally qualified health center in Los Angeles. Prevalence of GWG was inadequate, 22\%; adequate, 33\%; and excessive, $45 \%$. Risk factors for excessive GWG were hypertension $(p=.04)$, overweight $(p=.00)$, or obese pre-pregnancy BMI $(p=.01)$. Conversely, women who had gestational diabetes $(p=.02)$, ate more snacks $(p=.01)$, were multiparous $(p=.03)$, and less acculturated $(p=.03)$ experienced less excessive gain. Conclusions: Efforts to prevent excessive GWG in Mexican Americans should be targeted to women having their first baby and those with high pre-pregnancy BMI. One strategy may be recommending diet/exercise similar to that used in women with gestational diabetes. For women who are less acculturated and/or who are multiparous, strategies that will minimize inadequate GWG may improve newborn outcomes.
\end{abstract}

(c) 2015 Californian Journal of Health Promotion. All rights reserved.

Keywords: gestational weight gain, gestational diabetes, Mexican American, pregnancy, obesity, women

\section{Introduction}

Achieving adequate weight gain during pregnancy is critical to optimize infant and maternal outcomes (Institute of Medicine [IOM], 2009). However, only one third of women gain an appropriate amount of weight during pregnancy (Brawarsky et al., 2005; Schieve, Cogswell, \& Scanlon, 1998). Inadequate gestational weight gain (GWG) is mainly associated with poorer infant outcomes; preterm birth (Han et al., 2011) and suboptimal infant birth weight (Drehmer, Duncan, Kac, \& Schmidt, 2013; Han et al., 2011; Siega-Riz et al., 2009). Excessive GWG is also associated with negative infant outcomes such as perinatal mortality and excessive infant birth weights (March of Dimes, 2007; Siega-Riz, et al., 2009). In the mother, excessive GWG increases the likelihood of delivery complications (DeVader, Neeley, Myles, \& Leet, 2007; Rhodes, Schoendorf, \& Parker, 2003; Stotland, Hopkins, \& Caughey, 2004), postpartum weight retention
(Gore, Brown, \& West, 2003; Siega-Riz, et al., 2009), and subsequent obesity (Gunderson, Abrams, \& Selvin, 2000; Rooney \& Schauberger, 2002; Schmitt, Nicholson, \& Schmitt, 2007).

In the longer term, inadequate and excessive GWG appear to alter the fetal intrauterine environment, resulting in obesity in childhood (Salsberry \& Reagan, 2005), adolescence (Salsberry \& Reagan, 2007), and in Type 2 diabetes and atherogenic profiles in adulthood (Lau, Rogers, Desai, \& Ross, 2011; Rasmussen \& Yaktine, 2009). Therefore, optimizing GWG improves not only maternal health but that of the next generation.

\section{Ethnicity and Gestational Weight Gain}

Multiethnic studies have reported biologic, behavioral, psychological, and provider related factors associated with GWG (Althuizen, van Poppel, Seidell, \& van Mechelen, 2009; Brawarsky, et al., 2005; Chasan-Taber et al., 
2008; Dipietro, Millet, Costigan, Gurewitsch, \& Caulfield, 2003; Herring et al., 2012; Wells, Schwalberg, Noonan, \& Gabor, 2006). Among ethnic minority women, sociocultural factors must also be considered, for example, more obesogenic built environments (Booth, Pinkson, Walker, \& Poston, 2005; Lederman, Alfasi, \& Deckelbaum, 2002); culturally influenced dietary preferences such as home-prepared versus fast food (Carrera, Gao, \& Tucker, 2007; Gutierrez, 1999); beliefs about the amount of weight that should be gained, and which foods are either avoided or preferred during pregnancy (Tovar, Chasan-Taber, Bermudez, Hyatt, \& Must, 2010; Webb, Siega-Riz, \& Dole, 2009) all of which may increase vulnerability to inadequate and excessive GWG.

\section{Sociocultural Characteristics}

Acculturation. In Hispanics, acculturation into U.S. culture has been associated with negative prenatal behaviors such as alcohol use and smoking (Zambrana, Scrimshaw, Collins, \& Dunkel-Schetter, 1997) while preservation of the Mexican culture is evidenced by positive behaviors - healthy diets and avoidance of substances (Dixon, Sundquist, \& Winkleby, 2000). Subsequently, fewer perinatal complications and low birth weight infants are observed in less U.S.-acculturated women (Callister \& Birkhead, 2002). However, their wider age-range of childbearing results in more offspring, and greater exposure to the weight changes of pregnancy (Bowie et al., 2007).

Paternal education. As a proxy indicator of socioeconomic status, parental education may be associated with GWG (Williams and Collins, 2005). Lower education and poverty are associated with high body mass index (BMI), a key factor in excessive GWG (Drewnowski \& Specter, 2004; Herring et al., 2012; Molarius, Seidell, Sans, Tuomilehto, \& Kuulasmaa, 2000). In one study, parents with $12+$ years of education were more likely to have first-born infants who survived the first year of life. Stillbirth was 1.7 times more likely in families with a paternal education of less than 10 years, and 1.2 times more likely than when maternal education was less than 10 years (Arntzen, Magnus, \& Bakketeig, 1993). Hence, lower education, particularly paternal education, is associated with poorer living conditions, including reduced access to food and health care resources.

\section{Biologic Characteristics}

Maternal age. Adolescents and younger women (Deputy, Sharma, Kim, \& Hinkle, 2015; Howie, Parker, \& Schoendorf, 2003; Koleilat \& Whaley, 2013; Schieve et al., 1998) are more likely to gain excessively. Though related to concurrent maturation, it is of concern because of the risk of postpartum weight retention and the potential for young women to move to a high BMI category by the next pregnancy (Gould Rothberg et al., 2011). There is less consistency in older women. Deputy et al. (2015) reported that inadequate GWG was more likely in multiethnic women 35 and older while Puerto Rican women over 30 years of age were at 2.5 times greater risk for excessive GWG than younger women (ChasanTaber et al., 2008).

Pre-pregnancy body mass index. Prepregnancy BMI is a key predictor of GWG (IOM, 1990, 2009). High pre-pregnancy BMI is a recurring key determinant of excessive gain among non-Hispanic White (NHW) (Cogswell, Scanlon, Fein, \& Schieve, 1999; Harris, Ellison, \& Holliday, 1997; Olson \& Strawderman, 2003; Strychar et al., 2000); non-Hispanic Black (NHB) (Lederman et al., 2002), Hispanic (Chasan-Taber et al., 2008; Koleilat \& Whaley, 2013; Walker, Hoke, \& Brown, 2009) and multiethnic women (Brawarsky et al., 2005; Walker \& Kim, 2002; Wells et al., 2006). Specifically, overweight BMI has been the most commonly reported determinant of excessive GWG in all ethnicities (Brawarsky et al., 2005; Deputy et al., 2015; Nielsen et al., 2006; Olafsdottir, Skuladottir, Thorsdottir, Hauksson, \& Steingrimsdottir, 2006; Schieve et al., 1998). Conversely, underweight BMI has been implicated in increased risk of inadequate gain (Deputy et al., 2015), but with less frequency.

Parity. Large multiethnic studies of women of all ages have reported primiparity versus subsequent births as a covariate for excessive GWG (Abrams \& Parker, 1990; Brawarsky et al., 2005; Wells et al., 2006). Adolescent 
primiparas gained 5.28 pounds more than multiparas (Scholl et al., 1988); had twice the likelihood of excessive GWG than multiparas (Howie, et al., 2003) and Harris et al. (1997) reported primiparity as an independent predictor of excessive GWG followed by infant birth weight, and maternal BMI.

Hypertension. A relationship between hypertension in pregnancy and excessive GWG has been observed in women of diverse ethnicities (Caulfield, Witter, \& Stoltzfus, 1996; Johnson et al., 2013; Scholl et al., 1988; Wells et al., 2006). Compared to NHW women, NHB women consistently have more pregnancyrelated hypertension independent of other factors (Chappell et al., 2008; Knuist, Bonsel, Zondervan, \& Treffers, 1998; Liu et al., 2014). In Hispanics, findings are less consistent: from lower risk (Yeo, Wells, Kieffer, \& Nolan, 2007) to differential risk - higher risk for certain types of hypertension (e.g., preeclampsia but not gestational hypertension) (Wolf et al., 2004). In all ethnicities, pregnancy-related hypertension is more common in primiparas (Johnson et al., 2013) and in women with a family history of hypertension (Ness, Markovic, Bass, Harger, \& Roberts, 2003).

Excessive GWG and high pre-pregnancy BMI are modifiable factors that have independent as well as synergistic influences on hypertension in pregnancy. Hispanic women with excessive GWG had a three-fold risk of hypertension and four-fold risk of preeclampsia compared to women who gained appropriately. Those with obese pre-pregnancy BMI were 2.7 times greater risk of having pregnancy related hypertension than women in lower BMI categories (Fortner, Pekow, Solomon, Markenson, \& Chasan-Taber, 2009). In NHB women with obese BMI the risk of hypertension was 1.5 fold greater but when compounded by excessive GWG, increased to 2.6 fold (Chandrasekaran, Levine, Durnwald, Elovitz, \& Srinivas, 2014).

Gestational diabetes mellitus. Increased risk for gestational diabetes mellitus (GDM) is associated with excessive GWG in early pregnancy (Carreno et al., 2012; Hedderson, Gunderson, \& Ferrara, 2010). However, once diagnosed with GDM, Hispanic women may be more likely to gain inadequately (Walker et al., 2009) or adequately (Chasan-Taber et al., 2008) overall due to dietary and exercise modifications.

\section{Behavioral Characteristics}

Exercise. Physical activity varies by age, socioeconomic status, and acculturation. Hispanics are the most physically inactive ethnic group in the United States (Evenson \& Wen, 2010) and in pregnancy, expend 30\% less energy than NHW women (Schmidt, Pekow, Freedson, Markenson, \& Chasan-Taber, 2006). First generation Hispanic women who immigrated to the U.S. before 25 years of age and with greater English proficiency reported more physical activity than older women with less English (Evenson, Sarmiento, \& Ayala, 2004). Puerto Rican women most likely to engage in modest to more intense exercise were U.S. born, college-educated, had higher income, and fewer children compared to those more likely to engage in domestic activity who preferred Spanish and had more children (Chasan-Taber et al., 2007).

Maternal food intake. Although believed that more U.S.-acculturated Hispanic women take on the energy dense, high-fat diet common in young women in the U.S., this assumption is not well documented. In Mexican American adolescents, increasing GWG was positively associated with acculturation, but during pregnancy, they were more likely to eat traditional "more healthy" foods prepared by their mothers (Gutierrez, 1999). A review of acculturation and Hispanic food practices found no positive correlation between acculturation and dietary fat intake despite evidence that fatrelated behaviors differed based on acculturation. Less acculturated women consumed more whole milk and used fat in food preparation; whereas the more acculturated consumed more fast food, snacks, and added fats. More acculturated individuals consumed more fruit, rice, and beans and less acculturated individuals consumed less sugar and sugarsweetened beverages than more acculturated individuals (Ayala, Baquero, \& Klinger, 2008). Therefore, it may be that the overall dietary 
pattern and lifestyle of women with less acculturation (e.g., consuming foods with natural fat rather than added fats and a diet higher in fiber, Bacardi-Gascon, Dueñas-Mena, \& Jimenez-Cruz, 2007), in addition to physical work involved in food preparation, promotes adequate GWG.

\section{The Present Study}

In the United States, the Hispanic population is the fastest growing ethnic minority with the largest sub-groups being Mexican Americans (66\%) and Puerto Ricans (9\%) (Ennis, RíosVargas, \& Albert, 2011). However, perinatal differences exist among Hispanic sub-groups. Birth rates are highest in Mexican Americans (117 per 1,000) compared to Puerto Ricans (75.7) and Cubans (55.1, Bowie, Juon, Cho, \& Rodriquez, 2007), while preterm birth is highest in Puerto Ricans (14.0\%) and lowest in Central/South Americans (11.7\%) (March of Dimes, 2007).

Factors associated with GWG have been reported in other Hispanic sub-groups (ChasanTaber et al., 2008; Tovar et al., 2010; Tovar, Chasan-Taber, Bermudez, Hyatt, \& Must, 2012) but few studies have disaggregated Mexican women for study. It was hypothesized that a model of non-modifiable factors (age, parity, acculturation, paternal education), modifiable factors (pre-pregnancy BMI, exercise, maternal food intake), and covariates (hypertension, gestational diabetes) for GWG would identify Mexican women at risk for extremes of GWG who would benefit from strategies to promote healthy pregnancy gain.

\section{Methods}

\section{Design and Sample}

The study was a retrospective, correlational design. Data were obtained from patient records from a federally qualified health center in Los Angeles. The center has a busy women's health clinic where prenatal care is provided by nursemidwives and physicians. The majority of patients are low-income and Hispanic (84\%) (HRSA, 2014).
A purposive sample of Mexican/Mexican American women $(n=684)$ was achieved by screening 1,257 charts of women with Hispanic surnames who delivered infants between 2007 and 2009. Inclusion criteria were: term gestation (last prenatal visit $36+$ weeks), singleton, maternal age 12+ years old, ethnicity documented as Hispanic with place of birth in Mexico or the United States. If the chart indicated birthplace in U.S., the woman was contacted to determine self-identification as Mexican American. The chart had to include a pre-pregnancy weight or weight documented at $\leq 14$ weeks gestation. Charts were excluded if a pre-existing condition known to impair metabolism (e.g. thyroid disease and diabetes) was noted.

Charts analyzed must have indicated enrollment in the Comprehensive Perinatal Services Program (CPSP), a Medicaid case management program for pregnant women in California. Women enrolled in CPSP have provider prenatal visits and separate risk assessments inclusive of nutrition, health education, and psychosocial components.

\section{Procedures and Measures}

Data was manually extracted from medical records by the researcher and two registered nurses and entered onto a code sheet developed for the study. Data was extracted from: (a) the American College of Obstetrics and Gynecology (ACOG) Antepartum Record (ACOG, 2008), (b) CPSP Prenatal Combined Assessment/Reassessment Tool (CPSP, 1998), and (c) PFFQ (CPSP, 2004). The study protocol was approved by the Institutional Review Board of the investigators' affiliation as well as the health center.

\section{Variables}

The outcome variable, GWG, was measured by subtracting the self-reported pre-pregnancy weight from the last recorded maternal weight during the pregnancy. If pre-pregnancy weight was unknown, the first recorded weight during the first trimester was used. The latter was considered to be a reasonable approach as first trimester weight gain is minimal (Hytten, 1991; Picciano, 2007). 
GWG was categorized as inadequate, adequate, or excessive based on 2009 IOM guidelines which use pre-pregnancy BMI categories to determine adequate gain: underweight (BMI < $18.5 \mathrm{~kg} / \mathrm{m}^{2}$ ), 28 to 40 pounds; normal weight (BMI 18.5 - $24.99 \mathrm{~kg} / \mathrm{m}^{2}$ ), 25 to 35 pounds; overweight (BMI 25-29.9 $\mathrm{kg} / \mathrm{m}^{2}$ ), 15 to 25 pounds, and obese (BMI $\geq 30 \mathrm{~kg} / \mathrm{m}^{2}$ ), 11 to 20 pounds. Inadequate GWG was less than the recommendation in each BMI category, adequate GWG was within the recommendation, and excessive GWG was above the recommendation. Predictor variables: acculturation, paternal education, maternal age, pre-pregnancy BMI, parity, hypertension, gestational diabetes mellitus, exercise, and maternal food intake, were selected based on the review of the literature and their availability on the chart forms (Table 1).

Table 1.

Definitions of Predictor Variables

\begin{tabular}{|c|c|}
\hline Variable & Definition \\
\hline \multicolumn{2}{|l|}{ Sociocultural } \\
\hline Acculturation & $\begin{array}{l}\text { Preferred language at home (Cabassa, 2003) } \\
\text { - } \quad \text { Least (mother and father preferred Spanish) } \\
\text { - } \quad \text { Intermediate (mother and/or father preferred Spanish or English) } \\
\text { - } \quad \text { Most acculturated (mother and father preferred English). }\end{array}$ \\
\hline Paternal education & Number of years of school completed by father of woman's baby \\
\hline \multicolumn{2}{|l|}{ Biologic } \\
\hline Maternal age & Chronologic age at beginning of pregnancy \\
\hline Pre-pregnancy body mass index ${ }^{a}$ & $\begin{array}{l}\text { BMI prior to pregnancy = (weight in Pounds /(height in inches ) } \mathrm{x} \text { (height in } \\
\text { inches) } \mathrm{x} 703\end{array}$ \\
\hline Parity & $\begin{array}{l}\text { Number of term and preterm births achieving at least } 20 \text { weeks gestation } \\
\text { - } \quad \text { Primiparous - no prior infant of at least } 20 \text { weeks gestation (first baby) } \\
\text { - } \quad \text { Multiparous - one or more prior births of at least } 20 \text { weeks gestation }\end{array}$ \\
\hline Hypertension & $\begin{array}{l}\text { Blood pressure } \geq 140 \mathrm{~mm} \mathrm{Hg} \text { (systolic) and/or } \geq \text { to } 90 \mathrm{~mm} \mathrm{Hg} \text { (diastolic) prior } \\
\text { to or during pregnancy } \\
\text { "Yes" -any chronic hypertension and/or gestational hypertension. }\end{array}$ \\
\hline Gestational diabetes mellitus & $\begin{array}{l}\text { Impaired glucose tolerance that occurs during pregnancy (ACOG, 2013b) } \\
\text { - A1 - diet/exercise controlled } \\
\text { - A2 - use of oral agent (glyburide) } \\
\text { "Yes"- any of the above categories }\end{array}$ \\
\hline
\end{tabular}

Behavioral

Exercise

Maternal food intake ${ }^{\mathrm{d}}$
Reported number of minutes a day x reported number of days a week

Sum of the number of servings in food categories, protein, milk, grains, fruits and vegetables and fats and sweets, and snacks

Note: ${ }^{\mathrm{a}}$ If pre-pregnancy weight was unknown, first recorded prenatal weight during first trimester was used. ${ }^{\mathrm{b}}$ In pregnancy hypertension can be a preexisting condition or conditions, preeclampsia or gestational hypertension, that develop during pregnancy (ACOG, 2013b). ${ }^{\mathrm{c}}$ Excluded pre-existing diabetes. ${ }^{\mathrm{d}}$ Categories were determined with recommendation by expert registered dietician with a specialty in pregnancy nutrition and with comparison to the MyPyramid for Moms, the USDA macronutrient recommendations for pregnancy (U. S. Department of Agriculture, 2008). Each food intake variable was measured as servings per week except for snacks, snacks per day. ${ }^{\mathrm{e}}$ Content validity of questions selected for measurement of acculturation was based on Short Acculturation Scale for Hispanics (SASH), a 12-item scale widely used with Hispanics (Marin, Sabogal, Marin, Otero-Sabogal, \& Perez-Stable, 1987). SASH constructs are preferred language and language spoken with others (home and friends).

\section{Data Analysis}

Descriptive statistics were calculated on all variables of interest. A series of one-way
ANOVAs and chi-square tests of independence were conducted to examine whether there were systematic sociocultural, biologic, or behavioral differences among Mexican American women 
who experience inadequate, adequate, or excessive GWG (Tables 1-4).

In order to determine whether any of the characteristics identified in Tables 2-4 predicted Mexican American women's GWG, a multinomial logistic regression model was examined. Given the theoretical plausibility of each characteristic as predictors of GWG, it was decided a priori to include all statistically significant predictors from Tables 2-4 in the regression model. A $p$ value of less than or equal to .05 was considered statistically significant. SPSS version 20 was used for the analysis.

\section{Results}

In this group of Mexican American women, $22 \%$ gained less than recommended, $33 \%$ gained adequately, and $45 \%$ gained excessively. The mean age was 26.38 (SD $=6.48$ ), average number of prenatal visits was $12.73(\mathrm{SD}=3.00)$, and mean BMI was 27.09 (SD = 5.40). Most women $(81 \%)$ were born in Mexico $(p \leq .05)$ and had less than 12 years of education (64.4\%).
More of the Mexican born women (34.2\%) had adequate GWG than U.S. born (27.1\%). U.S. born women had more excessive GWG (55\%) than women born in Mexico (42.4\%). In contrast, more Mexican born women had inadequate gain $(23.4 \%)$ than U.S. born $(17.8 \%$, $p \leq .05)$.

\section{Sociocultural Characteristics}

Both sociocultural characteristics were significantly different in the three GWG categories (Table 2). Of Spanish only speaking women (least acculturated), 40.8\% gained excessively compared to $55.8 \%$ who spoke Spanish or English (moderately acculturated), and 53.6\% who spoke English only (most acculturated). More Spanish speaking women gained adequately (35.6\%) than Spanish or English (28.8\%) or English only (23.2\%). Mean paternal education was significantly different ( $p$ $\leq .001$ ) in that women with excessive GWG had partners with higher educational level $(9.83 \pm$ 2.64) compared to those with adequate $\left(9.05^{+}\right.$ $3.06)$ or inadequate $(8.84+2.91) \mathrm{GWG}$.

Table 2.

Sociocultural Characteristics by Gestational Weight Gain

\begin{tabular}{|c|c|c|c|c|}
\hline \multirow{2}{*}{$\begin{array}{l}\text { Sociocultural } \\
\text { Determinants }\end{array}$} & $\begin{array}{c}\text { Inadequate GWG } \\
n=153\end{array}$ & $\begin{array}{c}\text { Adequate GWG } \\
n=225\end{array}$ & $\begin{array}{c}\text { Excessive GWG } \\
n=306\end{array}$ & $F$ or $\chi^{2}$ \\
\hline & $\mathrm{n}(\%)$ or $\mathrm{M} \pm \mathrm{SD}$ & $\mathrm{n}(\%)$ or $\mathrm{M} \pm \mathrm{SD}$ & $\mathrm{n}(\%)$ or $\mathrm{M} \pm \mathrm{SD}$ & \\
\hline \multicolumn{5}{|l|}{ Acculturation } \\
\hline Spanish & $106(70.2)$ & $160(73.4)$ & $184(61.1)$ & $9.92 *$ \\
\hline Spanish or English & $32(21.2)$ & $45(20.6)$ & $87(28.9)$ & \\
\hline English & $13(8.6)$ & $13(6.0)$ & $30(10.0)$ & \\
\hline Paternal Education & $8.84 \pm 2.91$ & $9.05 \pm 3.06$ & $9.83 \pm 2.64$ & $6.82 * * *$ \\
\hline$<12$ years & $86(70.5)$ & $126(67.4)$ & $162(62.3)$ & 2.81 \\
\hline$\geq 12$ years & $36(29.5)$ & $61(32.6)$ & $98(37.7)$ & \\
\hline
\end{tabular}

$* p \leq .05 * * p \leq .01 * * * p \leq .001$

\section{Biologic Characteristics}

The three GWG categories were significantly different for biologic characteristics of prepregnancy BMI, parity, hypertension, and GDM (Table 3). Adequate GWG occurred most often $(41.6 \%)$ in women who were underweight or of normal weight prior to pregnancy. Excessive gain occurred most frequently in women who were overweight $(63.5 \%)$ or obese $(42.2 \%)$ at pregnancy onset. Very few women $(n=10)$ |
Women with normal pre-pregnancy BMI more commonly had adequate GWG (41.3\%) than those with overweight (25.3\%) or obese BMI (30.1\%). Of the study's 199 primiparous women, 109 (54\%) gained too much and by parity, comprised the majority (58.3\%) in the excessive gain group. Hypertension was also most common in women with excessive GWG. Inadequate gain was more common in women with GDM, in particular those managed with diet or oral medication. Of the 74 women with 
Table 3.

Biologic Characteristics by Gestational Weight Gain

\begin{tabular}{|c|c|c|c|c|}
\hline \multirow{2}{*}{ Biologic Determinants } & $\begin{array}{c}\text { Inadequate GWG } \\
n \mathrm{n}=153\end{array}$ & $\begin{array}{c}\text { Adequate GWG } \\
n=225\end{array}$ & $\begin{array}{c}\text { Excessive GWG } \\
n=306\end{array}$ & \multirow[t]{2}{*}{$F$ or $\chi^{2}$} \\
\hline & $\mathrm{n}(\%)$ or $\mathrm{M} \pm \mathrm{SD}$ & $\mathrm{n}(\%)$ or $\mathrm{M} \pm \mathrm{SD}$ & $\mathrm{n}(\%)$ or $\mathrm{M} \pm \mathrm{SD}$ & \\
\hline Age (years) & $27.32 \pm 6.37$ & $26.30 \pm 6.23$ & $25.98 \pm 6.68$ & 2.20 \\
\hline$<20$ & $18(11.8)$ & $37(16.4)$ & $62(20.3)$ & 6.36 \\
\hline $20-35$ & $115(75.2)$ & $167(74.2)$ & $211(69.2)$ & \\
\hline$>35$ & $20(13.1)$ & $21(9.3)$ & $32(10.5)$ & \\
\hline Pre-Pregnancy BMI & $27.55 \pm 6.66$ & $26.29 \pm 5.26$ & $27.46 \pm 4.70$ & $3.80 *$ \\
\hline Underweight & $4(40.0)$ & $5(50.0)$ & $1(10.0)$ & $69.01 * * *$ \\
\hline Normal & $75(29.0)$ & 107 (41.3) & 77 (29.7) & \\
\hline Overweight & $28(11.2)$ & $63(25.3)$ & $158(63.5)$ & \\
\hline Obese & $46(27.7)$ & $50(30.1)$ & $70(42.2)$ & \\
\hline \multicolumn{5}{|l|}{ Parity } \\
\hline Primiparous & 30 (19.9) & $60(26.7)$ & 109 (35.7) & $13.36 * *$ \\
\hline Multiparous & $121(80.1)$ & 165 (73.3) & $196(64.3)$ & \\
\hline \multicolumn{5}{|c|}{ Hypertension (dichotomous) } \\
\hline No & $141(92.8)$ & $211(93.8)$ & $268(87.6)$ & $6.87 *$ \\
\hline Yes & $11(7.2 \%)$ & $14(6.2)$ & $38(12.4)$ & \\
\hline \multicolumn{5}{|l|}{ Gestational Diabetes } \\
\hline No & 119 (79.3) & 199 (88.8) & $287(94.1)$ & $26.25 * * *$ \\
\hline A1 & $14(9.3)$ & 7 (3.1) & $5(1.6)$ & \\
\hline A2, glyburide & $13(8.7)$ & $14(6.3)$ & $9(3.0)$ & \\
\hline A2, insulin & $4(2.7)$ & $4(1.8)$ & $4(1.3)$ & \\
\hline \multicolumn{5}{|l|}{$\begin{array}{l}\text { Gestational Diabetes } \\
\text { (dichotomous) }\end{array}$} \\
\hline No & 119 (79.3) & 199 (88.8) & 287 (94.1) & $22.60 * * *$ \\
\hline Yes & 31 (20.7) & $25(11.2)$ & 18 (5.9) & \\
\hline
\end{tabular}

${ }^{*} p \leq .05 * * p \leq .01 * * * p \leq .001$

GDM, 40\% gained inadequately, 33\% gained adequately, and $24 \%$ gained excessively $p<$ $.001)$.

\section{Behavioral Characteristics}

The GWG categories were significantly different $(p \leq .001)$ for one behavioral characteristic snacks per day (Table 4). Women with inadequate GWG ate more snacks per day $(2.13$ $\pm 0.99)$ than women with adequate GWG $(2.03$ $\pm 0.92)$ or with excessive GWG $(1.75 \pm 1.04)$. Among the three categories, there were no significant differences in exercise, maternal food intake, or intake of specific food groups.

\section{Determinants of Gestational Weight Gain}

Multinomial logistic regression modeling revealed several statistically significant predictors of inadequate and excessive GWG $\left(\chi^{2}(18)=126.04, \mathrm{p}<.001\right)$.

Table 5 shows that inadequate GWG was associated with multiparity $(\mathrm{OR}=2.09)$ and was less likely in women with less acculturation (OR $=0.50$ ).

Determinants of excessive weight gain were hypertension $(\mathrm{OR}=2.16)$ and high prepregnancy BMI; overweight $(\mathrm{OR}=4.65)$ or obese ( $\mathrm{OR}=2.17$ ) as compared to normal prepregnancy BMI. Protective factors for excessive gain were GDM $(\mathrm{OR}=0.41)$, multiparity $(\mathrm{OR}=$ $0.47)$, less acculturation $(\mathrm{OR}=0.57)$ and eating more snacks per week $(\mathrm{OR}=0.96)$. 
Table 4.

Behavioral Characteristics by Gestational Weight Gain

\begin{tabular}{|c|c|c|c|c|}
\hline \multirow[t]{2}{*}{ Behavioral Determinants } & $\begin{array}{c}\text { Inadequate GWG } \\
n=153\end{array}$ & $\begin{array}{c}\text { Adequate GWG } \\
\mathrm{n}=225\end{array}$ & $\begin{array}{c}\text { Excessive GWG } \\
\mathrm{n}=306\end{array}$ & \multirow[t]{2}{*}{$F$ or $\chi^{2}$} \\
\hline & $\mathrm{n}(\%)$ or $\mathrm{M} \pm \mathrm{SD}$ & $\mathrm{n}(\%)$ or $\mathrm{M} \pm \mathrm{SD}$ & $\mathrm{n}(\%)$ or $\mathrm{M} \pm \mathrm{SD}$ & \\
\hline Exercise (minutes/wk) & $119.51 \pm 126.73$ & $136.42 \pm 182.45$ & $117.36 \pm 145.90$ & 1.00 \\
\hline $0-50$ & $48(34.0)$ & $76(36.2)$ & $108(37.5)$ & 4.56 \\
\hline 51-100 & $30(21.3)$ & 48 (22.9) & $55(19.1)$ & \\
\hline $101-150$ & 27 (19.1) & 30 (14.3) & $59(20.5)$ & \\
\hline$>150$ & $36(25.5)$ & $56(26.7)$ & $66(22.9)$ & \\
\hline $\begin{array}{l}\text { Maternal food intake } \\
\text { (servings/wk) }\end{array}$ & $138.54 \pm 31.85$ & $140.48 \pm 33.17$ & $136.86 \pm 34.43$ & 0.75 \\
\hline Protein & $14.03 \pm 6.60$ & $15.14 \pm 7.22$ & $14.77 \pm 6.24$ & 1.27 \\
\hline$<16$ & $100(65.8)$ & $140(62.2)$ & 182 (59.7) & 3.63 \\
\hline $16-28$ & $50(32.9)$ & $78(34.7)$ & $118(38.7)$ & \\
\hline$>28$ & $2(1.3)$ & $7(3.1)$ & $5(1.6)$ & \\
\hline Milk & $16.37 \pm 7.51$ & $17.37 \pm 8.78$ & $16.79 \pm 8.48$ & 0.69 \\
\hline$<16$ & $66(43.4)$ & 97 (43.1) & $124(40.7)$ & 1.64 \\
\hline $16-28$ & 78 (51.3) & $112(49.8)$ & $165(54.1)$ & \\
\hline$>28$ & $8(5.3)$ & $16(7.1)$ & $16(5.2)$ & \\
\hline Grain & $42.63 \pm 16.61$ & $44.34 \pm 16.10$ & $41.99 \pm 18.15$ & 1.24 \\
\hline$<38$ & $54(35.5)$ & $76(33.8)$ & $106(34.8)$ & 0.67 \\
\hline $38-65$ & 85 (55.9) & $129(57.3)$ & $177(58.0)$ & \\
\hline$>65$ & $13(8.6)$ & $20(8.9)$ & $22(7.2)$ & \\
\hline Fruits \& vegetables & $38.91 \pm 15.73$ & $37.67 \pm 15.98$ & $38.36 \pm 15.03$ & \\
\hline$<21$ & $10(6.6)$ & $13(5.8)$ & $20(6.6)$ & 0.30 \\
\hline $21-49$ & $115(75.7)$ & $178(79.1)$ & $240(78.7)$ & 0.94 \\
\hline$>49$ & 27 (17.8) & 34 (15.1) & $45(14.8)$ & \\
\hline Fats \& sweets & $10.72 \pm 9.23$ & $11.83 \pm 10.13$ & $12.74 \pm 10.51$ & 2.05 \\
\hline$<3$ & $21(14.0)$ & $22(9.8)$ & $19(6.3)$ & 8.87 \\
\hline $3-12$ & $70(46.7)$ & $121(54.0)$ & $156(51.5)$ & \\
\hline$>12$ & 59 (39.3) & $81(36.2)$ & $128(42.2)$ & \\
\hline Snacks per day & $2.13 \pm 0.99$ & $2.03 \pm 0.92$ & $1.75 \pm 1.04$ & $8.97 * * *$ \\
\hline 0 & $6(4.3)$ & $18(8.1)$ & $52(17.2)$ & $25.28 * * *$ \\
\hline $1-2$ & $88(63.3)$ & $149(67.1)$ & $195(64.4)$ & \\
\hline$>2$ & $45(32.4)$ & $55(24.8)$ & $56(18.5)$ & \\
\hline
\end{tabular}

\section{Discussion}

This is the first known study to document prevalence of GWG in a homogeneous group of Mexican/Mexican American women. The finding that one third of the women in this study gained adequately is consistent with previous literature regarding women of all ethnicities (Barbara Abrams, Altman, \& Pickett, 2000; Caulfield et al., 1996; Cogswell et al., 1999; Olson \& Strawderman, 2003). It is also consistent with older studies of other Hispanic groups in the United States: $33 \%$ in Puerto Ricans ( Chasan-Taber et al., 2008); 32\% in Hispanics in the San Francisco area (Brawarsky et al., 2005) and 33.9\% in Hispanic women in New Mexico (Walker et al., 2009).
During the study period, the IOM released new GWG guidelines that use World Health Organization BMI categories instead of the previous ones based on the Metropolitan Life insurance tables (IOM, 2009). These classify smaller proportions of women as underweight before pregnancy while a larger proportion are classified as overweight. The limitations of comparing this sample to older studies are that the 2009 IOM guidelines result in fewer women with inadequate GWG and more women with excessive GWG than if the 1990 IOM guidelines were applied. 
Table 5.

Summary of Multinomial Regression Models for Determinants of Inadequate and Excessive Gestational Weight Gain $(n=553)$

\begin{tabular}{|c|c|c|c|c|c|}
\hline Determinants & $\beta$ & SE $\beta$ & $\operatorname{Exp}(\beta)$ & \multicolumn{2}{|c|}{$95 \% \mathrm{CI}$} \\
\hline IGWG vs. AGWG & & & & $L L$ & $U L$ \\
\hline Snacks per Week & .01 & .02 & 1.01 & 0.98 & 1.05 \\
\hline Paternal Education & -.02 & .24 & 0.64 & 0.36 & 1.13 \\
\hline Gestational Diabetes & .53 & .36 & 1.69 & 0.84 & 3.41 \\
\hline Hypertension & -.04 & .49 & 0.96 & 0.37 & 2.50 \\
\hline Pre-pregnancy BMI ${ }^{\mathrm{b}}$ & & & & & \\
\hline Underweight & -.46 & .89 & 0.60 & 0.11 & 3.61 \\
\hline Overweight & -.42 & .32 & 0.19 & 0.35 & 1.22 \\
\hline Obese & .17 & .31 & 0.58 & 0.65 & 2.16 \\
\hline Acculturation & -69 & .31 & $0.50^{*}$ & 0.27 & 0.91 \\
\hline Parity $^{\mathrm{d}}$ & .74 & .34 & $2.09 *$ & 1.07 & 4.08 \\
\hline EGWG vs. AGWG & & & & $L L$ & $U L$ \\
\hline Snacks per Week & -.04 & .01 & $0.96 * *$ & 0.93 & 0.99 \\
\hline Paternal Education & -.02 & .24 & 0.98 & 0.62 & 1.55 \\
\hline Gestational Diabetes & -.90 & .38 & $0.41 *$ & 0.19 & 0.86 \\
\hline Hypertension & .77 & .37 & $2.16 *$ & 1.04 & 4.48 \\
\hline Pre-pregnancy BMI ${ }^{\mathrm{b}}$ & & & & & \\
\hline Underweight & -2.05 & 1.16 & 0.13 & 0.01 & 1.23 \\
\hline Overweight & 1.54 & .25 & $4.65 * * *$ & 2.82 & 7.66 \\
\hline Obese & .78 & .28 & $2.17 * *$ & 1.24 & 3.80 \\
\hline Acculturation & -.56 & .25 & $0.57 *$ & 0.35 & 0.94 \\
\hline Parity $^{\mathrm{d}}$ & -.75 & .25 & $0.47 * * *$ & 0.29 & 0.78 \\
\hline
\end{tabular}

${ }^{*} p \leq .05 * * p \leq .01 * * * p \leq .001$

Note: $R^{2}=.20$ (Cox and Snell), .23 (Nagelkerke). Model $\chi^{2}(18)=126.04, p<.001$.

${ }^{a}$ Reference category: Less than 12 years education

${ }^{\mathrm{b}}$ Reference category: Normal

${ }^{\mathrm{c}}$ Reference category: Least acculturated

${ }^{\mathrm{d}}$ Reference category: Primiparity

Our study had a larger proportion of Mexican American women who gained adequately and a smaller proportion who gained excessively compared to recent large multi-ethnic studies (Hunt, Alanis, Johnson, Mayorga, \& Korte, 2013; Chihara et al., 2014). Compared to a study of Hispanics in Texas, our sample had fewer women with inadequate gain, more women with adequate gain, and similar prevalence of excessive gain (Sangi-Haghpeykar, Lam, \& Raine, 2014). The positive differences may be due to the large proportion of less acculturated women in our sample who were less likely to gain excessively and more likely to have adequate weight gain than more acculturated. System factors- easily accessed prenatal care, case management, and the provision of multilayered care by providers, health educators, and support staff at the center could also be influential in these differences.

\section{Models of Gestational Weight Gain}

Models of GWG using sociocultural, biologic, behavioral, and variables have been proposed. In NHW women, Olson and Strawderman (2003) described a "biopsychosocial model" that explained $27 \%$ of the variance in overall GWG. 
Factors associated with greater GWG were decreased physical activity, consuming more food, overweight pre-pregnancy BMI, and low income while factors associated with inadequate GWG were low BMI, consuming less food, and smoking. Models of GWG in Hispanic women have been reported in Puerto Ricans in Massachusetts (Chasan-Taber et al., 2008); Hispanics in New Mexico (Walker et al., 2009) and in Houston, Texas (Sangi-Haghpeykar, Lam, \& Raine, 2014). In the Latina GDM Study, Chasan-Taber et al. (2008) found that older maternal age, more prenatal visits, overweight, parity and acculturation were associated with both inadequate and excessive GWG among Puerto Rican women. In our study, predictor variables accounted for $20 \%$ of the variance in the model of GWG in Mexican American women and are described in the next section.

Acculturation. Less acculturation to the U.S. was protective of both extremes of GWG. This finding is partially consistent among Puerto Ricans, in which U.S.-born women were more likely to gain excessively (Chasan-Taber et al., 2008), and women with less than 10 years of U.S. residence were less likely to gain excessively (Tovar et al., 2012). Similarly, more acculturated (U.S. born) Hispanic women in Houston, Texas were more than 3 times likely to gain excessively (Sangi-Haghpeykar et al., 2014) than non-U.S. born, and Spanish speaking Hispanic women in Southern California were about half as likely to have excessive GWG. Our study found that Mexican women with less acculturation were also less likely to have inadequate GWG - a finding not previously reported.

Hypertension. Recent national attention to identification and treatment of hypertensive disorders during pregnancy compels health workers to be aware of its associated factors. In our study, Mexican American women with hypertension were twice as likely to have excessive GWG. This is an important finding in that excessive GWG is modifiable and can be influenced by correct advice and information (Cogswell et al., 1999; Stotland et al., 2005). Therefore, preconception interventions for women with high BMI as well as strategies to promote adequate gain in pregnancy may be a double-pronged approach to decreasing the incidence of hypertension in pregnancy.

Parity. In our study, women in their first pregnancy were more likely to gain excessively. This is consistent with studies which have suggested that the first/ index pregnancy has higher GWG than subsequent pregnancies in multiethnic women (Brawarsky et al., 2005; Wells et al., 2006) and in Puerto Ricans (Chasan-Taber et al., 2008).

Recent studies of NHW primiparas reported excessive gains of $74.3 \%$ and $74 \%$ (Chung et al., 2013; Restall et al., 2014) - higher than reports from older studies which may in part reflect the application of the 2009 GWG guidelines. In comparison, in our study, $54.7 \%$ of primiparous women gained excessively, which is still of great concern because women of minority groups are more likely to retain excess postpartum weight than NHW women (Gould Rothberg, et al., 2011; Walker, Freeland-Graves, Milani, George, et al., 2004).

Snack consumption. Snack consumption was the only behavioral variable related to GWG. Mexican women consuming more snacks per week were less likely to have excessive gain during pregnancy. In contrast, studies of NHW women and adolescents have not reported this association (Olson \& Strawderman, 2003; Stevens-Simon \& McAnarney, 1992). Our finding is consistent with a recent study in which pregnant women with high pre-pregnancy BMI were randomized to a treatment group of which part was to consume three meals and three snacks each day (Petrella et al., 2014). Women in the treatment group had lower GWG than those in the control group. The hypothetical basis for our finding is suggested in the next section.

Gestational diabetes mellitus. In our study, women with GDM were $60 \%$ less likely to have excessive GWG. Our findings were unlike Walker et al. (2009), who found that Hispanic women with GDM were more likely to have inadequate gain. However, Chasan-Taber et al. (2008) reported that more Puerto Rican women 
achieved adequate GWG when they had GDM than those without GDM.

Women with GDM have more difficulty metabolizing carbohydrates than pregnant women in general. This results in high maternal levels of glucose which may result in larger infants with more body fat. To promote euglycemia, women with GDM engage in medical nutrition therapy and daily exercise (American Diabetes Association, 2012). In practice, three meals and two to three snacks daily are recommended to distribute glucose intake and to reduce postprandial glucose fluctuations. Daily exercise is recommended to improve glycemic control (ACOG, 2013a). The fact that women with GDM experience such dietary/activity treatment, and are more closely monitored than women without GDM, suggests the benefit of lifestyle modifications and increased vigilance with respect to pregnancy weight gain.

Pre-pregnancy body mass index. The key predictor of excessive gain in Mexican American women was high BMI - being overweight and obese at the beginning of pregnancy (4.65 and 2.17 times) compared to women with normal BMI. This is similar to, but more extreme than in Hispanic women in New Mexico (Walker et al., 2009). As women with normal pre-pregnancy BMI have reduced risk of preterm birth compared to those with lower or higher BMIs, this further reinforces the benefit of achieving optimal pre-pregnancy BMI (Kosa et al., 2011). Therefore, preconception health promotion should be directed to Mexican American women with overweight prepregnancy BMI, given their propensity to gain excessively, compounded with increased risk for postpartum retention (Walker, Freeland-Graves, Milani, Hanss-Nuss et al., 2004), which increases the likelihood of obese pre-pregnancy BMI (Gould Rothberg, et al., 2011) in subsequent pregnancies.

\section{Study Strengths and Limitations}

Study data was abstracted from the ACOG Antepartum Record and forms used for the California Comprehensive Perinatal Services Program which were designed to assess individual pregnant women's health, obstetrical, psychosocial and nutritional risk. No other studies to date were found in which these tools were used to study a minority population such as Mexican American women.

Study limitations were that the retrospective design limited the analysis to available data in clinic records. Although tools such as that used for food intake in this study have the advantages of suggesting dietary patterns over an extended period (a week in this study), disadvantages include uncertain validity, inadequate food lists (particularly culturally specific foods), and inconsistent estimate of portion sizes (Fowles, Sterling, \& Walker, 2007). Further, as the study was conducted in a health clinic with a majority of low-income Hispanics, it does not represent the Mexican American population across socioeconomic spectra.

Interaction effects were not examined due to the exploratory nature of this study. For instance with advancing age and subsequent pregnancies, pre-pregnancy BMI also increases (Bowie et al., 2007). As discussed, sociocultural factors such as acculturation and paternal education influence biologic and behavioral variables. Future research may build upon the initial predictors identified in this study, with thought given to inclusion of other known interaction effects.

\section{Conclusion}

Of all women, Mexican American women experience pregnancy most often and therefore are most vulnerable to the effects of GWG. The study reported a model of GWG to identify Mexican women at risk for extremes of GWG who could benefit from strategies to promote healthy pregnancy gain. Key factors associated with gaining excessively; high pre-pregnancy BMI and primiparity alert the clinician to provide early prenatal information on GWG and to seek additional support (dietician, group classes, pregnancy exercise/Zumba) for the woman with high BMI and/or is a first time mother. The relationship between hypertension and excess GWG encourages vigilance for hypertension when excess gain is developing as 
well as supports efforts to prevent excess gain which may reduce hypertension.

Postpartum care should target women who have gained excessively and/or started in a high prepregnancy category by concerted support to exclusively breastfeed for at least six months; resume/initiate some form of cardiovascular exercise; and ensure that she has been given the option of a long acting reversible contraceptive. Women with GDM were less likely to gain excessively - therefore a similar diet and exercise regimen may have the same result in women who are at greater risk for excessive gain who do not have GDM. Multiparous women were more likely to gain inadequately than primiparous so they should be provided with education that will encourage behaviors to achieve optimal gain. Low acculturation conferred protection against both extremes of GWG. This may be another aspect of the
Hispanic paradox in which the adherence to traditional behaviors contributes to better health outcomes. Continued research is needed to identify strategies that resonate with Mexican/Mexican women, especially those at particular risk for extremes of weight gain; to promote health of the woman, her baby, and subsequent generations.

\section{Acknowledgements}

The project was supported by an Azusa Pacific University Doctoral Scholarship and California State Fullerton, New Faculty Scholarship. Acknowledgements are extended to Cheryl Westlake, PhD, RN, CNS for her assistance and support during my doctoral dissertation and to the administrators and staff at Eisner Pediatric \& Family Medical Center who approved the research protocol. We also acknowledge the invaluable editing provided by Dana Rutledge, $\mathrm{PhD}, \mathrm{RN}$.

\section{References}

Abrams, B., Altman, S. L., \& Pickett, K. E. (2000). Pregnancy weight gain: still controversial. American Journal of Clinical Nutrition, 71(Supplement), 1233-1241.

Abrams, B., \& Parker, J. D. (1990). Maternal weight gain in women with good pregnancy outcome. Obstetrics and Gynecology, 76(1), 1-7.

ACOG. (2013a). Practice Bulletin No. 137: Gestational diabetes mellitus. Obstetrics \& Gynecology, 122(2, PART 1), 406-416.

ACOG. (2013b). Hypertension in pregnancy: Executive summary. Obstetrics \& Gynecology, 122(5), 1122-1131.

Althuizen, E., van Poppel, M. N. M., Seidell, J. C., \& van Mechelen, W. (2009). Correlates of absolute and excessive weight gain during pregnancy. Journal of Women's Health (15409996), 18(10), 1559-1566. doi: 10.1089/jwh.2008.1275

American College of Obstetrics \& Gynecology. (2008). ACOG Antepartum Record. Retrieved from http://www.acog.org/About-ACOG/ACOG-Departments/Health-InformationTechnology/ACOG-Antepartum-Form-and-EMRs

American Diabetes Association. (2012). Standards of Medical Care in Diabetes-2012. Diabetes Care, 35 (Supplement 1), S11-S63. doi: 10.2337/dc12-s011

Arntzen, A., Magnus, P., \& Bakketeig, L. S. (1993). Different effects of maternal and paternal education on early mortality in Norway. Paediatric And Perinatal Epidemiology, 7, 376-386.

Ayala, G. X., Baquero, B., \& Klinger, S. (2008). A systematic review of the relationship between acculturation and diet among Latinos in the United States: Implications for future research. Journal of the American Dietetic Association, 108(8), 1330-1344. doi: http://dx.doi.org/10.1016/j.jada.2008.05.009

Bacardi-Gascon, M., Dueñas-Mena, D., \& Jimenez-Cruz, A. (2007). Lowering effect on postprandial glycemic response of nopales added to Mexican breakfasts. Diabetes Care, 30(5), 1264-1265. doi: 10.2337/dc06-2506

Booth, K. M., Pinkson, M. M., Walker, S., \& Poston, C. (2005). Obesity and the built environment. Journal of the American Dietetic Association, 105, S110-S117. 
Bowie, J. V., Juon, H., Cho, J., \& Rodriquez, E. M. (2007). Factors associated with overweight and obesity among Mexican Americans and Central Americans: Results from the 2001 California Health Interview Survey [Serial Online]. . Preventing Chronic Disease: Public Health Research, Practice, and Policy. Retrieved from http://www.cdc.gov/pcd/issues/2007/jan/06_0036.htm.

Brawarsky, P., Stotland, N. E., Jackson, R. A., Fuentes-Afflick, E., Escobar, G., Rubashkin, N., \& Haas, J. S. (2005). Pre-pregnancy and pregnancy-related factors and the risk of excessive or inadequate gestational weight gain. International Journal of Gynecology and Obstetrics, 91, 125-131.

Cabassa, L., J. (2003). Measuring acculturation: Where we are and where we need to go. Hispanic Journal of Behavioral Sciences, 25, 127-145.

Callister, L. C., \& Birkhead, A. (2002). Acculturation and perinatal outcomes in Mexican immigrant women: An integrative review. Journal of Perintal and Neonatal Nursing, 16(3), 22-38.

Carreno, C. A., Clifton, R. G., Hauth, J. C., Myatt, L., Roberts, J. M., Spong, C. Y., . . Human Development Maternal-Fetal Medicine Units Network. (2012). Excessive early gestational weight gain and risk of gestational diabetes mellitus in nulliparous women. Obstetrics \& Gynecology, 119(6), 1227-1233.

Carrera, P. M., Gao, X., \& Tucker, K. L. (2007). A study of dietary patterns in the Mexican-American population and their association with obesity. Journal of the American Dietetic Association, 107, 1735-1742.

Caulfield, L. E., Witter, F. R., \& Stoltzfus, R. (1996). Determinants of gestational weight gain outside the recommended ranges among white and black women. Obstetrics \& Gynecology, 87(5), 760-766.

Chandrasekaran, S., Levine, L. D., Durnwald, C. P., Elovitz, M. A., \& Srinivas, S. K. (2014). Excessive weight gain and hypertensive disorders of pregnancy in the obese patient. The Journal of Maternal-Fetal \& Neonatal Medicine, 1-5. Retrieved from http://informahealthcare.com/doi/abs/10.3109/14767058.2014.939624 doi:10.3109/14767058.2014.939624

Chappell, L. C., Enye, S., Seed, P., Briley, A. L., Poston, L., \& Shennan, A. H. (2008). Adverse perinatal outcomes and risk factors for preeclampsia in women with chronic hypertension: A prospective study. Hypertension, 51(4), 1002-1009. doi: 10.1161/hypertensionaha.107.107565

Chasan-Taber, L., Schmidt, M. D., Pekow, P., Sternfeld, B., Manson, J., \& Markenson, G. (2007). Correlates of physical activity in pregnancy among Latina women. Maternal and Child Health Journal, 11(4), 353-363.

Chasan-Taber, L., Schmidt, M. D., Pekow, P., Sternfeld, B., Solomon, C. G., \& Markenson, G. (2008). Predictors of excessive and inadequate gestational weight gain in Hispanic women. Obesity (Silver Spring, Md.), 16(7), 1657-1666.

Chihara, I., Hayes, D. K., Chock, L. R., Fuddy, L. J., Rosenberg, D. L., \& Handler, A. S. (2014). Relationship between gestational weight gain and birthweight among clients enrolled in the Special Supplemental Nutrition Program for Women, Infants, and Children (WIC), Hawaii, 2003-2005. Maternal and Child Health Journal, 18(5), 1123-1131. doi: 10.1007/s10995-0131342-6

Chung, J. G. Y., Taylor, R. S., Thompson, J. M. D., Anderson, N. H., Dekker, G. A., Kenny, L. C., \& McCowan, L. M. E. (2013). Gestational weight gain and adverse pregnancy outcomes in a nulliparous cohort. European Journal of Obstetrics \& Gynecology and Reproductive Biology, 167(2), 149-153. doi: http://dx.doi.org/10.1016/j.ejogrb.2012.11.020

Cogswell, M. E., Scanlon, K. S., Fein, S. B., \& Schieve, L. A. (1999). Medically advised, mother's personal target, and actual weight gain during pregnancy. Obstetrics and Gynecology, 94(4), 616622.

Comprehensive Perinatal Services Program. (1998). CPSPCombined Assessment/Reassessment Tool. Retrieved November 3, 2014, from http://publichealth.lacounty.gov/mch/cpsp/forms/pnasse 1.pdf 
Comprehensive Perinatal Services Program. (2004). Perinatal Food Frequency Questionnaire Retrieved November 3, 2014, from http://publichealth.lacounty.gov/mch/cpsp/forms/PFFQ_Eng\&Span_Blank.pdf

Deputy, N. P., Sharma, A. J., Kim, S. Y., \& Hinkle, S. N. (2015). Prevalence and characteristics associated with gestational weight gain adequacy. Obstetrics \& Gynecology, 125(4), 773-781.

DeVader, S. R., Neeley, H. L., Myles, T. D., \& Leet, T. L. (2007). Evaluation of gestation weight gain guidelines for women with normal prepregnancy body mass index. Obstetrics \& Gynecology, 110(4), 745-751.

Dipietro, J. A., Millet, S., Costigan, K. A., Gurewitsch, E., \& Caulfield, L. E. (2003). Psychosocial influences on weight gain attitudes and behaviors during pregnancy. Journal of the American Dietetic Association, 103(10), 1314-1319.

Dixon, L. B., Sundquist, J., \& Winkleby, M. (2000). Differences in energy, nutrient, and Ffood intakes in a US sample of Mexican-American women and men: Findings from the Third National Health and Nutrition Examination Survey, 1988-1994. American Journal of Epidemiology, 152(6), 548557. doi: 10.1093/aje/152.6.548

Drehmer, M., Duncan, B. B., Kac, G., \& Schmidt, M. I. (2013). Association of Second and Third Trimester Weight Gain in Pregnancy with Maternal and Fetal Outcomes. [Article]. PLoS ONE, 8(1), 1-8. doi: 10.1371/journal.pone.0054704

Drewnowski, A., \& Specter, S. E. (2004). Poverty and obesity: the role of energy density and energy costs. American Journal Clinical Nutrition, 79, 6 -16.

Ennis. S. R., Ríos-Vargas, M., \& Albert, N. G. (2011). The Hispanic Population: 2010 Census Briefs. United States Census Bureau.

Evenson, K. R., Sarmiento, O. L., \& Ayala, G. X. (2004). Acculturation and physical activity among North Carolina Latina immigrants. Social Science \& Medicine (1982), 59(12), 2509-2522.

Evenson, K. R., \& Wen, F. (2010). National trends in self-reported physical activity and sedentary behaviors among pregnant women: NHANES 1999-2006. Preventive Medicine, 50(3), 123-128. doi: http://dx.doi.org/10.1016/j.ypmed.2009.12.015

Fortner, R. T., Pekow, P., Solomon, C. G., Markenson, G., \& Chasan-Taber, L. (2009). Prepregnancy body mass index, gestational weight gain, and risk of hypertensive pregnancy among Latina women. American Journal of Obstetrics and Gynecology, 200(2), 167.e161-167.

Fowles, E. R., Sterling, B. S., \& Walker, (2007). Measuring dietary intake in nursing research. Canadian Journal of Nursing Research, 39(2), 146-165.

Gore, S. A., Brown, D. M., \& West, D. S. (2003). The role of postpartum weight retention in obesity among women: a review of the evidence. Annals Of Behavioral Medicine: A Publication Of The Society Of Behavioral Medicine, 26(2), 149-159.

Gould Rothberg, E., B., Magriples, U., Kershaw, T. S., Rising, S. S., \& Ickovics, J. R. (2011). Gestational weight gain and subsequent postpartum weight loss among young, low-income, ethnic minority women. American Journal of Obstetrics and Gynecology, 204(1), 52.e51-52.e11. doi: http://dx.doi.org/10.1016/j.ajog.2010.08.028

Gunderson, E. P., Abrams, B., \& Selvin, S. (2000). The relative importance of gestational gain and maternal characteristics associated with the risk of becoming overweight after pregnancy. International Journal of Obesity, 24, 1660-1668.

Gutierrez, Y. M. (1999). Cultural factors affecting diet and pregnancy outcome of pregnant adolescents. Journal of Adolescent Health, 25, 227-237.

Han, Z., Lutsiv, O., Mulla, S., Rosen, A., Beyene, J., \& McDonald, S. D. (2011). Low gestational weight gain and the risk of preterm birth and low birthweight: a systematic review and meta-analyses. [Article]. Acta Obstetricia et Gynecologica Scandinavica, 90(9), 935-954. doi: 10.1111/j.16000412.2011.01185.x

Harris, H. E., Ellison, G. T., \& Holliday, M. (1997). Is there an independent association between parity and maternal weight gain? Annals Of Human Biology, 24(6), 507-519. 
Hedderson, M. M., Gunderson, E. P., \& Ferrara, A. (2010). Gestational weight gain and risk of gestational diabetes mellitus. Obstetrics \& Gynecology, 115(3), 597-604.

Herring, S. J., Nelson, D. B., Davey, A., Klotz, A. A., Dibble, L. V., Oken, E., \& Foster, G. D. (2012). Determinants of excessive gestational weight gain in urban, low-income women. Women's Health Issues, 22(5), e439-e446. doi: http://dx.doi.org/10.1016/j.whi.2012.05.004

Howie, L. D., Parker, J. D., \& Schoendorf, K. C. (2003). Excessive maternal weight gain patterns in adolescents. Journal of the American Dietetic Association, 103(12), 1653-1657.

HRSA. (2014). 2013 Health Center Profile - Eisner Pediatric \& Family Medical Center. Retrieved November 3, 2014, from http://bphc.hrsa.gov/uds/datacenter.aspx?q=d\&bid=0921340\&state=CA

Hunt, K. J., Alanis, M. C., Johnson, E. R., Mayorga, M. E., \& Korte, J. E. (2013). Maternal prepregnancy weight and gestational weight gain and their association with birthweight with a focus on racial differences. Maternal and Child Health Journal, 17(1), 85-94. doi: 10.1007/s10995012-0950-x

Hytten, F. E. (1991). Weight gain in pregnancy. In F. E. Hytten \& G. Chamberlain (Eds.), Clinical Physiology in Obstetrics London: Blackwell Scientific Publications.

Institute of Medicine. (1990). Nutrition in pregnancy: Part 1-Weight Gain. Washington, D.C.: National Academy Press.

Institute of Medicine. (2009). Weight Gain During Pregnancy: Reexamining the Guidelines. Washington, D.C. : The National Academies Press.

Johnson, J., Clifton, R. G., Roberts, J. M., Myatt, L., Hauth, J. C., Spong, C. Y., . . Human Development Maternal-Fetal Medicine Units, N. (2013). Pregnancy outcomes with weight gain above or below the 2009 IOM guidelines. Obstetrics and Gynecology, 121(5), 969-975. doi: 10.1097/AOG.0b013e31828aea03

Knuist, M., Bonsel, G. J., Zondervan, H. A., \& Treffers, P. E. (1998). Risk factors for preeclampsia in nulliparous women in distinct ethnic groups: A prospective cohort study. Obstetrics \& Gynecology, 92(2), 174-178.

Koleilat, M., \& Whaley, S. (2013). Trends and predictors of excessive gestational weight gain among Hispanic WIC participants in Southern California. Maternal and Child Health Journal, 17(8), 1399-1404. doi: 10.1007/s10995-012-1140-6

Kosa, J., Guendelman, S., Pearl, M., Graham, S., Abrams, B., \& Kharrazi, M. (2011). The association between pre-pregnancy BMI and preterm delivery in a diverse southern California population of working women. Maternal and Child Health Journal, 15(6), 772-781. doi: 10.1007/s10995-0100633-4

Lau, C., Rogers, J. M., Desai, M., \& Ross, M. G. (2011). Fetal programming of adult disease: Implications for prenatal care. Obstetrics \& Gynecology, 117(4), 978-985.

Lederman, S. A., Alfasi, G., \& Deckelbaum, R. J. (2002). Pregnancy-associated obesity in black women in New York City. Maternal and Child Health Journal, 6(1), 37-42.

Liu, J., Gallagher, A. E., Carta, C. M., Torres, M. E., Moran, R., \& Wilcox, S. (2014). Racial differences in gestational weight gain and pregnancy-related hypertension. Annals of Epidemiology, 24(6), 441-447. doi: http://dx.doi.org/10.1016/j.annepidem.2014.02.009

March of Dimes. (2007). Born too soon: Prematurity in the U.S. Hispanic population March of Dimes. White Plains, NY.

Marin, G., Sabogal, F., Marin, B. V., Otero-Sabogal, R., \& Perez-Stable, E. (1987). Development of a short acculturation scale for Hispanics. Hispanic Journal of Behavioral Sciences, 9(183-203).

Molarius, A., Seidell, J. C., Sans, S., Tuomilehto, J., \& Kuulasmaa, K. (2000). Educational level, relative body weight and changes in their association over 10 years: An international perspective from the WHO MONICA project. American Journal of Public Health, 90(8), 1260-1268.

Ness, R. B., Markovic, N., Bass, D., Harger, G., \& Roberts, J. M. (2003). Family history of hypertension, heart disease, and stroke among women who develop hypertension in pregnancy. Obstetrics And Gynecology, 102(6), 1366-1371. 
Nielsen, J. N., O'Brien, K., Witter, F. R., Chang, S.-C., Mancini, J., Nathanson, M. S., \& Caulfield, L. E. (2006). High gestational weight gain does not improve birth weight in a cohort of African American adolescents. American Journal Clinical Nutrition, 84, 183-189.

Olafsdottir, A. S., Skuladottir, G. V., Thorsdottir, I., Hauksson, A., \& Steingrimsdottir, L. (2006). Maternal diet in early and late pregnancy in relation to weight gain. International Journal of Obesity (2005), 30(3), 492-499.

Olson, C. M., \& Strawderman, M. S. (2003). Modifiable behavioral factors in a biopsychosocial model predict inadequate and excessive gestational weight gain. Journal of the American Dietetic Association, 103(1), 48-54.

Petrella, E., Malavolti, M., Bertarini, V., Pignatti, L., Neri, I., Battistini, N. C., \& Facchinetti, F. (2014). Gestational weight gain in overweight and obese women enrolled in a healthy lifestyle and eating habits program. The Journal of Maternal-Fetal \& Neonatal Medicine, 27(13), 1348-1352. doi: doi:10.3109/14767058.2013.858318

Picciano, M. F. (2007). Pregnancy and lactation: Physiological adjustments, nutrtitional requirements and the role of dietary supplements. The Journal of Nutrition, 133(Supplement), 1997-2002.

Rasmussen, K. M., \& Yaktine, A. L. (Eds.). (2009). Weight Gain During Pregnancy: Reexamining the Guidelines (Prepublication copy ed.). Washington, D.C.: National Academies Press.

Restall, A., Taylor, R. S., Thompson, J., Flower, D., Dekker, G. A., Kenny, L. C., . . McCowan, L. (2014). Risk factors for excessive gestational weight gain in a healthy, nulliparous cohort. Journal of Obesity, 2014, 148391. doi: 10.1155/2014/148391

Rhodes, J. C., Schoendorf, K. C., \& Parker, J. D. (2003). Contribution of excess weight during pregnancy and macrosomia to the cesarean delivery rate. Pediatrics, 111(5), 1181-1185.

Rooney, B. L., \& Schauberger, C. W. (2002). Excess pregnancy weight gain and long-term obesity: One decade later. Obstetrics \& Gynecology, 100(2), 245-252.

Salsberry, P. J., \& Reagan, P. B. (2005). The dynamics of early childhood overweight. Pediatrics, 116 (6), 1329-1338.

Salsberry, P. J., \& Reagan, P. B. (2007). Taking the long view: The prenatal environment and early adolescent overweight. Research in Nursing and Health, 30, 297-307.

Sangi-Haghpeykar, H., Lam, K., \& Raine, S. P. (2014). Gestational weight gain among Hispanic women. Maternal and Child Health Journal, 18(1), 153-160. doi: 10.1007/s10995-013-1248-3

Schieve, L., Cogswell, M., \& Scanlon, K. (1998). Trends in pregnancy weight gain within and outside ranges recommended by the IOM in a WIC population. Matern Child Health J, 2, 111 - 116.

Schmidt, M. D., Pekow, P., Freedson, P. S., Markenson, G., \& Chasan-Taber, L. (2006). Physical activity patterns during pregnancy in a diverse population of women. Journal Of Women's Health (2002), 15(8), 909-918.

Schmitt, N., Nicholson, W., \& Schmitt, J. (2007). The association of pregnancy and the development of obesity - results of a systematic review and meta-analysis on the natural history of postpartum weight retention. Int J Obes (Lond), 31, 1642 - 1651.

Scholl, T. O., Salmon, R. W., Miller, L. K., Vasilenko, P., 3rd, Furey, C. H., \& Christine, M. (1988). Weight gain during adolescent pregnancy. Associated maternal characteristics and effects on birth weight. Journal Of Adolescent Health Care: Official Publication Of The Society For Adolescent Medicine, 9(4), 286-290.

Siega-Riz, A. M., Viswanathan, M., Moos, M.-K., Deierlein, A., Mumford, S., Knaack, J., ... Lohr, K. N. (2009). A systematic review of outcomes of maternal weight gain according to the IOM recommendations: birthweight, fetal growth, and postpartum weight retention. American Journal of Obstetrics and Gynecology, 201(4), 339.e331-339.e314. doi: http://dx.doi.org/10.1016/j.ajog.2009.07.002

Stevens-Simon, C., \& McAnarney, E. R. (1992). Determinants of weight gain in pregnant adolescents. Journal of the American Dietetic Association, 92(11), 1348-1351. 
Stotland, N. E., Haas, J. S., Brawarsky, P., Jackson, R. A., Fuentes-Afflick, E., \& Escobar, G. (2005). Body mass index, provider advice, and target gestational weight gain. Obstetrics \& Gynecology, 105(3), 633-638.

Stotland, N. E., Hopkins, L. M., \& Caughey, A., B. (2004). Gestational weight gain, macrosomia, and the risk of cesarean birth in nondiabetic nulliparas. Obstetrics \& Gynecology, 104, 671-677.

Strychar, I. M., Chabot, C., Champagne, F., Ghadirian, P., Leduc, L., Lemonnier, M. C., \& Raynauld, P. (2000). Psychosocial and lifestyle factors associated with insufficient and excessive maternal weight gain during pregnancy. Journal of the American Dietetic Association, 100(3), 353-356.

Tovar, A., Chasan-Taber, L., Bermudez, O., Hyatt, R., \& Must, A. (2010). Knowledge, attitudes, and beliefs regarding weight gain during pregnancy among Hispanic women. Maternal and Child Health Journal, 14(6), 938-949. doi: 10.1007/s10995-009-0524-8

Tovar, A., Chasan-Taber, L., Bermudez, O., Hyatt, R., \& Must, A. (2012). Acculturation and gestational weight gain in a predominantly Puerto Rican population. BMC Pregnancy and Childbirth, 12(1), 1-10. doi: 10.1186/1471-2393-12-133

U. S. Department of Agriculture. (2008). My Pyramid Plan for Moms. Retrieved from http://www.mypyramid.gov/mypyramidmoms/index.html

Walker, L., Freeland-Graves, J. H., Milani, T., George, G., Hanss-Nuss, H., Kim, M., . . Stuifbergen, A. (2004). Weight and behavioral and psychosocial factors among ethinically diverse, low-income women after childbirth: II. Trends and correlates. Women and Health, 40(2), 19-34.

Walker, L., Freeland-Graves, J. H., Milani, T., Hanss-Nuss, H., George, G., Sterling, B. S., .. . Stuifbergen, A. (2004). Weight and behavioral and psychosocial factors among ethinically diverse, low-income women after childbirth: I. Methods and context. Women and Health, 40(2), $1-17$.

Walker, L. O., Hoke, M. M., \& Brown, A. (2009). Risk factors for excessive or inadequate gestational weight gain among Hispanic women in a U.S.-Mexico border state. Journal of Obstetric, Gynecologic, \& Neonatal Nursing, 38(4), 418-429. doi: 10.1111/j.1552-6909.2009.01036.x

Walker, L. O., \& Kim, M. (2002). Psychosocial thriving during late pregnancy: relationship to ethnicity, gestational weight gain, and birth weight. Journal Of Obstetric, Gynecologic and Neonatal Nursing: JOGNN / NAACOG, 31(3), 263-274.

Webb, J. B., Siega-Riz, A. M., \& Dole, N. (2009). Psychosocial determinants of adequacy of gestational weight gain. Obesity (Silver Spring, Md.), 17(2), 300-309.

Wells, C. S., Schwalberg, R., Noonan, G., \& Gabor, V. (2006). Factors influencing inadequate and excessive weight gain in pregnancy: Colorado, 2000-2002. Maternal \& Child Health Journal, 10(1), 55-62.

Williams, D. R., \& Collins, C. (2005). U.S. Socioeconomic and racial differences in health: Patterns and explanations. In T. LaViest (Ed.), Minority Populations and Health: An Introduction to Health Disparities in the United States. San Francisco: Jossey-Bass.

Wolf, M., Shah, A., Jimenez-Kimble, R., Sauk, J., Ecker, J. L., \& Thadhani, R. (2004). Differential risk of hypertensive disorders of pregnancy among Hispanic women. Journal of the American Society of Nephrology, 15(5), 1330-1338. doi: 10.1097/01.asn.0000125615.35046.59

Yeo, S., Wells, P., Kieffer, E., \& Nolan, G. (2007). Preeclampsia among Hispanic women in a Detroit health system. Ethnicity \& Disease, 17(1), 118-121.

Zambrana, R. E., Scrimshaw, S. C. M., Collins, N., \& Dunkel-Schetter, C. (1997). Prenatal health behaviors and psychosocial risk factors in pregnant women of Mexican origin: The role of acculuration. American Journal of Public Health, 87, 1022-1026. 
Author Information

Ruth Mielke, PhD, CNM, FACNM, WHNP*

Assistant Professor

California State University, Fullerton - School of Nursing Coordinator of the Women's Health Care Concentration 800 N. State College Road

Fullerton, CA 92831

ruthmielke@fullerton.edu

Office: 657-278-2670 Fax: 657-278-3338

Nicholas Gorman, EdD, MPH

Assistant Professor

California State University, Fullerton School of Nursing

* corresponding author 